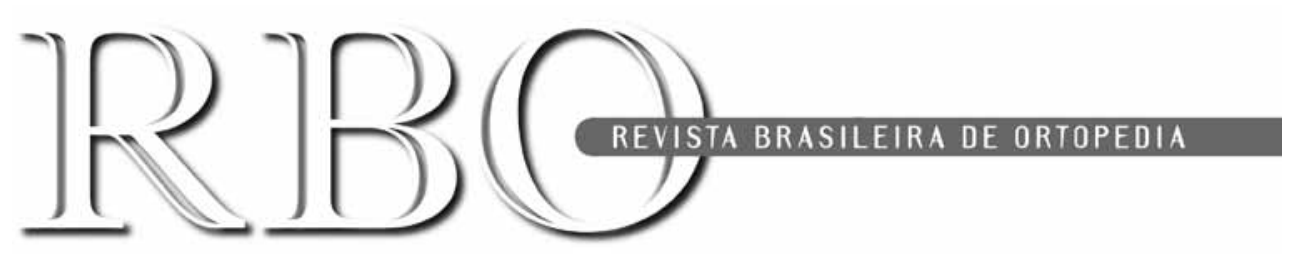

\title{
Editorial
}

\section{TRIBUTE - THE MAN WHO CHANGED THE FACE OF ORTHOPEDICS}

Our specialization is still in its infancy. We have, perhaps, just one generation of orthopedists who were trained specifically in this branch of medicine.

Our principles are based mostly on the experiences and practices of pioneers, who entered the area of orthopedics coming from other areas of medicine.

Some of its dogmas are very old and have not yet been replaced.

In traumatic and orthopedic pathology of the shoulder, a man emerged to change and create new concepts - Charles S. Neer.

$R B O$ pays him a tribute with this summary of his life, written by Osvandré Lech.

Gilberto Luis Camanho

\section{Charles S. Neer}

"He has truly made outstanding contributions that have brought clarity out of chaos in the variou areas of shoulder surgery. His publications are voluminous, and each article is written accurately, clearly and with obvious attention to every detail. His versatility as a teacher, researcher, and surgeon is far excellence". (Texto do Clinical Orthopaedics and Related Research, 1987).

Professor Charles S. Neer II was born on November 10, 1917 and died on February 28, 2011 on the same rural estate, in Vinita, Oklahoma, USA. A son and grandson of doctors, he studied at Dartmouth College, at the University of Pennsylvania Medical School, and at the Columbia-Presbyterian Medical Center, where he began his internship, finally becoming a Professor Emeritus, culminating in an impressive academic career. He was a surgeon in the US Army during the Second World War, stationed in Europe, Japan and the Philippines.

After the war, he returned to Columbia University, where he

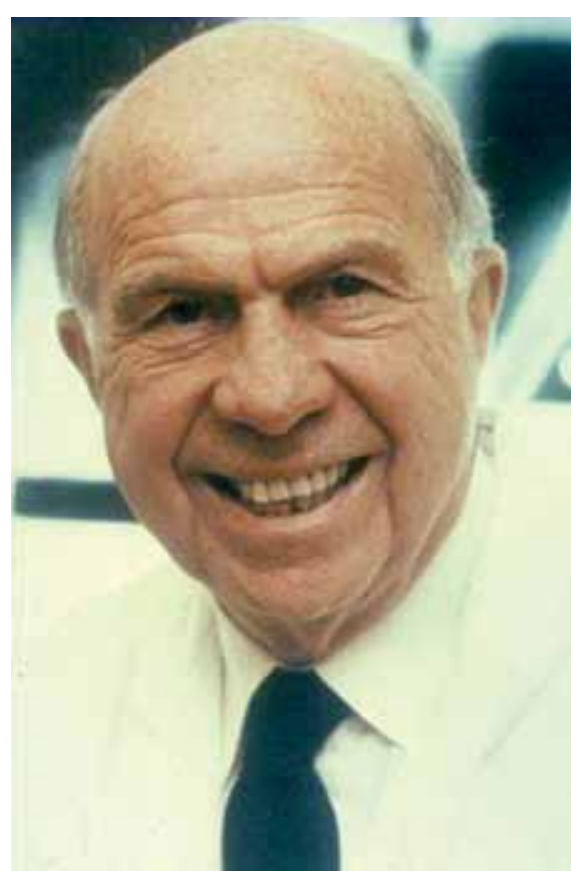


became head of the Fracture Service, and then of the Adult Orthopedic Service. In 1955, he started the biggest transformation ever seen in shoulder surgery with the introduction of partial arthroplasty. In 1963, he took part in the "first meeting" of shoulder surgery in Toronto, Canada, where there were more lecturers than listeners... D'Aubigné, De Palma, Mac Laughlin, Rowe, Julius Nevasier, and Jobe were present, among others. In 1969 he chaired the Board of Directors of the AAOS and the AOA, simultaneously.

In 1976 he established the first fellowship in surgery of the shoulder and elbow of the USA, which was awarded to Rockwood, Cofield, Russel Warren, Bigliani, Fukuda, Ed Craig, David Morrison, Evan Flatow, among others. In 1982, he founded the American Shoulder and Elbow Surgeons (ASES), becoming its first President. In 1987, Clinical Orthopaedics and Related Research dedicated a volume to his by now considerable contribution to the world of shoulder surgery - partial, then total arthroplasty, classification of proximal fractures of the humerus, classification of distal fractures of the clavicle, the concept of Impingement Syndrome and the pathology of the rotator cuff, the importance of the os acromiale as a predisposing factor of lesion of the rotator cuff, the modern concepts of instability and luxation of the shoulder, the definition of multidirectional instability and cuff tear arthropathy, and the importance of postoperative rehabilitation. In short, Dr. Neer published prolifically over a period spanning 50 years, modifying concepts and altering paradigms in this new area of orthopedic knowledge. For 30 years he was the most sought-after lecturer in the area, and an Inaugural Speaker at the majority of societies of the shoulder worldwide, including the South American Society for Surgery of the Shoulder and Elbow, held in Salvador, Brazil, in 1994.

It is known, though never confirmed, that he sold the copyright for his prosthesis for a nominal value of $\$ 1$ (one dollar) to the company 3M. Even doing so, from a moral perspective, he had the right to lecture and present scientific works on the prosthesis, without engendering any conflict of interest. It is not known for certain whether this really took place in the 1970s, but it would be unthinkable in this third millennium...

In 1985, he made a huge donation to the development of shoulder research, establishing the Neer Award, which is the most important annual award of the ASES. In 1989, he chaired the IV International Congress of Surgery of the Shoulder (ICSS), in New York. In 1992, he founded the International Board and the Board of Trustees of the Journal of Shoulder and Elbow Surgery, giving rise to the first journal dedicated exclusively to surgery of the shoulder and elbow. He has received commendations, tributes and honorific titles in various countries. If you type "Charles S. Neer" into Google, it brings up 6,920,000 citations. He rounded off his glorious academic career with the book Shoulder Reconstruction, written without collaborators, in 1990. Exaggeration aside, there is probably no chapter or article on shoulder surgery that has been written after the 1980s that does not mention his name.

Charles Neer was someone who preferred not to converse, so as not to lose the thread of a line of reasoning that he had been developing for several days on some point of view; someone who washed his own patient before surgery; someone who did not agree when the point of view did not corresponded exactly to his own; someone who responded the question asked... the next day! As a human being, he was unique. Loved or hated, but always respected. After retirement, he decided to return to his beloved Vinita, where he lived a simple, healthy life, beside his wife Eileen and their children, until passing away of natural causes, at the age of 94.

The man has gone, but his work remains. And that is the most important part of a man.

Resquiast in Pace, Professor Neer. 